\title{
Jet Stream as a Major Factor of Tornados in USA
}

\author{
Igor G. Zurbenko, Mingzeng Sun \\ Department of Epidemiology and Biostatistics, State University of New York at Albany, New York, USA \\ Email: igorg.zurbenko@gmail.com, msun@albany.edu
}

Received 3 February 2016; accepted 9 April 2016; published 12 April 2016

Copyright $\odot 2016$ by authors and Scientific Research Publishing Inc.

This work is licensed under the Creative Commons Attribution International License (CC BY). http://creativecommons.org/licenses/by/4.0/

(c) (i) 0pen Access

\begin{abstract}
Using the Modern-Era Retrospective Analysis for Research and Applications (MERRA) reanalysis data resources for the period 1979 to 1988, we defined the spatial distribution and temporal trends of jet stream by month, and analyzed geographic distribution of the smoothed hourly wind speed of jet stream in May, after applied Kolmogorov-Zurbenko Adaptive (KZA) filter. We showed the impressive synchronousness between hourly tornado risks and diurnal distribution of top 3 maximum daily wind speed of jet stream over USA. We observed that latitudinal distribution of jet stream concurrently oscillated with latitudinal distribution of tornado outbreaks. KZA filter smoothed spatial distribution of jet stream on tornado days showed a substantial increase in presence of jet stream over tornado alley region, compared to that on non-tornado-days.
\end{abstract}

\section{Keywords}

Jet Stream, Tornado, KZA Filter

\section{Introduction}

\subsection{Tornadoes Are Powerful and Deadly, but Unpredictable Weather Phenomena}

The National Weather Service (NWS) defines a tornado (Figure 1) as a violently spinning funnel-shaped air extending from the base of a thunderstorm down to the ground [1]. Tornadoes, descending like titans from the clouds, tearing down buildings and lashing out at their surroundings, are capable of completely destroying well-made structures, uprooting trees, taking human lives and hurling objects through the air like deadly missiles (Figure 2 and Figure 3). It is estimated that each year in the United States, 1000 tornadoes on average kill about 70 people, injure 1500, and cause roughly $\$ 400$ million in damages [2] [3]. The year 2011 was especially vicious, with a record-breaking 1691 tornadoes killing 550 people, causing more than $\$ 25$ billion in damages [4].

The very nature of tornadoes makes them the wildcard of weather disasters. Unlike forecasting other weather 


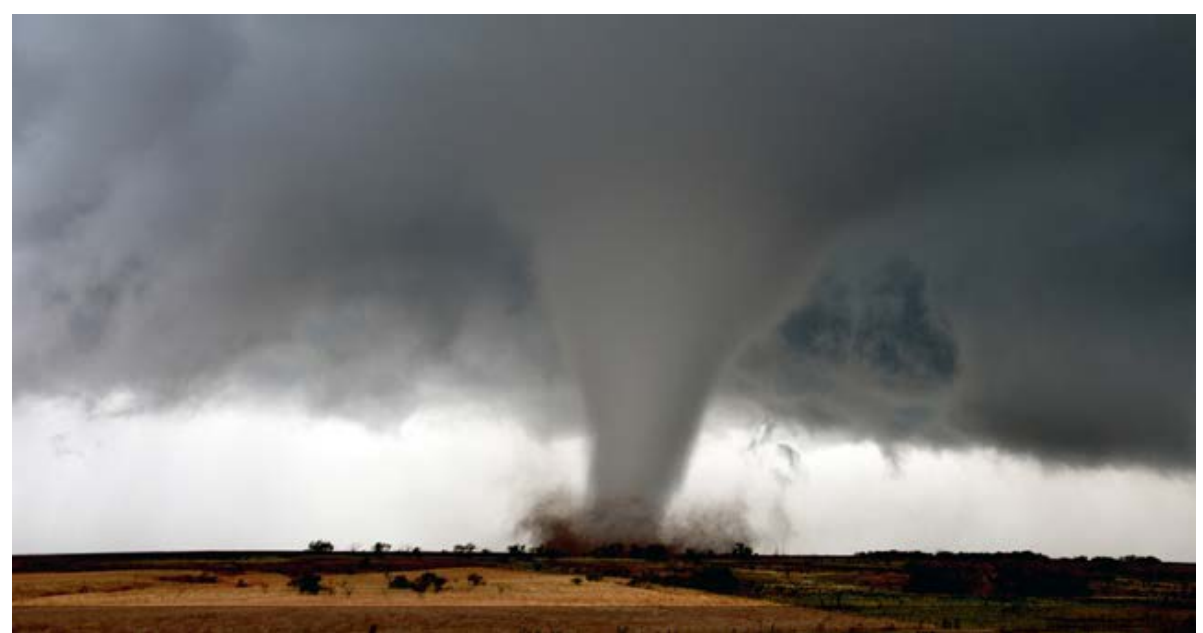

Figure 1. Tornadoes-National weather service. http://www.nws.noaa.gov/os/severeweather/

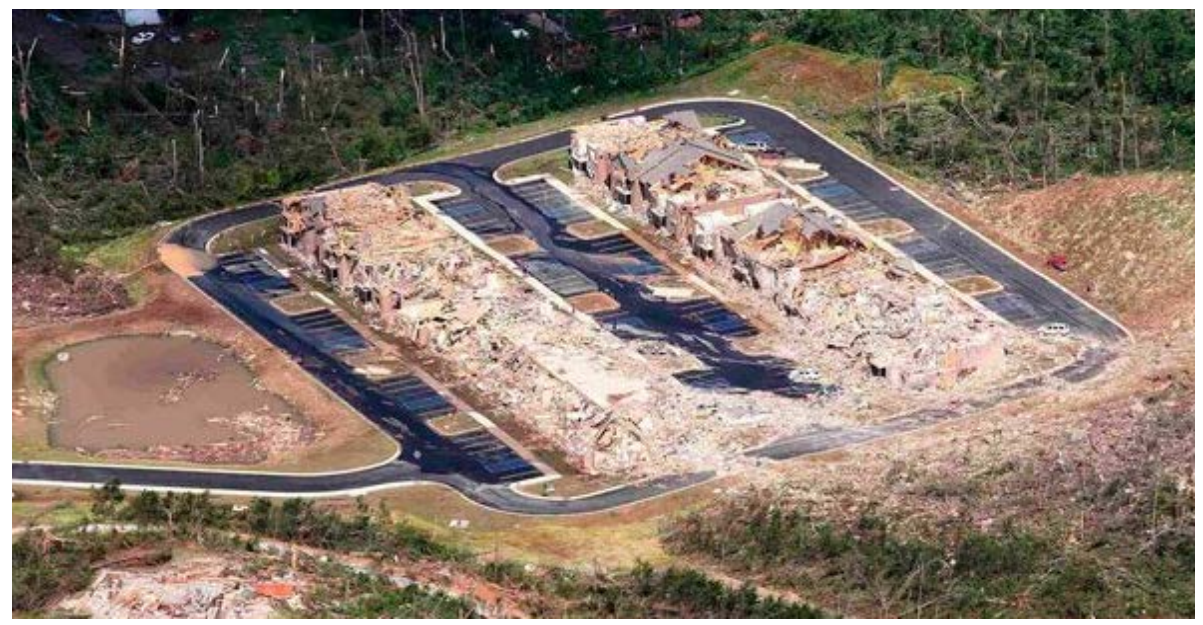

Figure 2. A tornado completely leveled an apartment complex in Tuscaloosa, Ala. (April 28, 2011). New York Times. http://www.nytimes.com/2011/04/29/us/29storm.html?_r=0

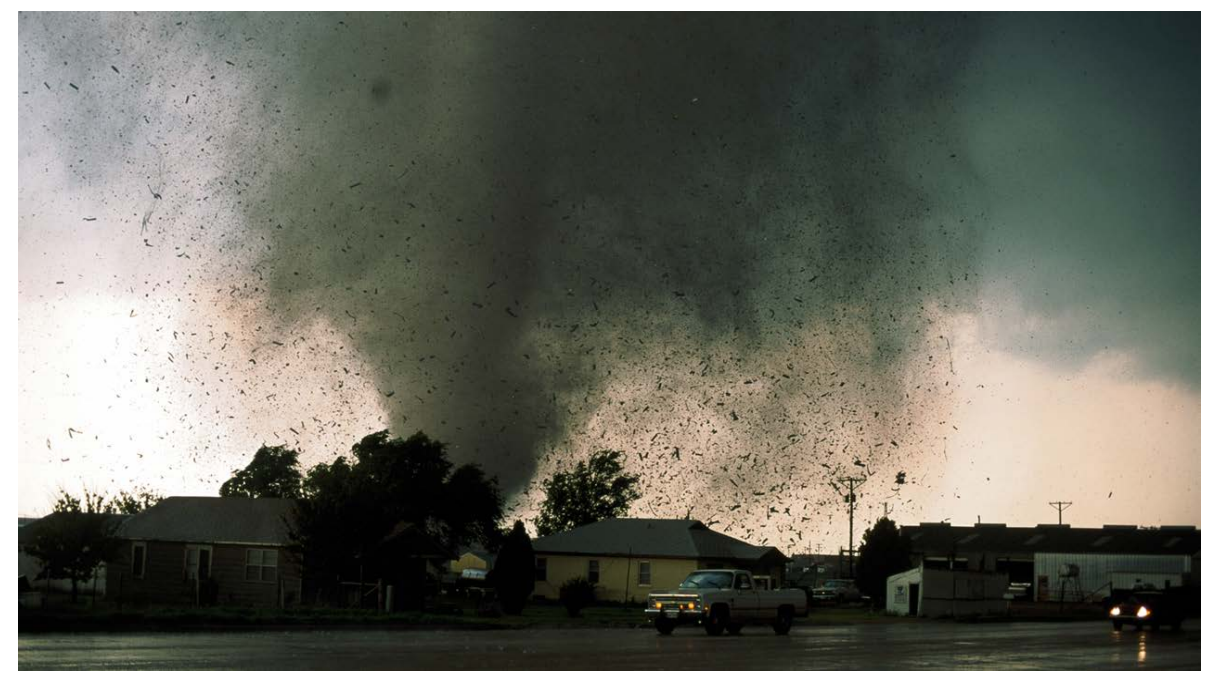

Figure 3. A tornado was razing the neighborhoods. NOVA-PBS http://www.pbs.org/wgbh/nova/earth/deadliest-tornadoes.html 
systems such as hurricane, it is just hard to figure when and where tornadoes will appear. Tornadoes are pretty localized in general, with a relatively small path and lasting for only short periods of time.

Set aside its unpredictable features, tornadoes occur regularly each year in many parts of the world. These powerful tornadoes have been reported on almost every continent [5]; but the United States experiences the most, especially in the so called "Tornado-Alley" area [6]. Although it has occurred at any time of the day, any day of the year, most likely tornadoes occur in the late-afternoon, generally 3-8 PM [7].

\subsection{How a Tornado Is Formed}

Tornado formation requires necessary factors, such as air temperature, moisture, density, and wind flow are in place. Many theories have been developed and none has been accepted generally by scientists in this field [8]. During the past decades, there have been numerous studies in this country aimed at assessing the tornado formation and/or tornado evolution for selected tornadoes [9]-[14]. These studies have individually assessed the tornado genesis process of specific tornadoes. For example, based on an integrated analysis of the synoptic and subsynoptic overview of jet stream, thunderstorm, and thermodynamic fields in the event, Corfiti and his colleagues reconstructed the process of the super outbreak of tornadoes on 3-4 April 1974 over the central and eastern United States [13]. These studies provided with the detailed estimations, such as the major factors/conditions contributed to each unique tornado outbreaks. However, the existing studies suggest that each tornado outbreak was developed through a unique combination of potential ingredients; their holistic features relevant to tornado occurrence were missing.

\subsection{Existing of Jet Stream Is the Key Culprit in Tornado Development}

Water vapor is considered as major source of dynamics in atmospheric processes. Tropical area is receiving major part of sun radiation and is working as an essential vapor generator over our planet. In our previous study we found that in summer, the difference of specific humidity $(\mathrm{SH})$ between equator and mid latitude is at least 10 units (g water vapor/kg of air mass) [15]. This is indicating that a certain volume of vapor (corresponding to at least 10 units of $\mathrm{SH}$ ) would collapse due to vapor vanish, while the air mass is transporting from equator to mid-latitudes at the same temperature; Actual decrease of temperature from equator to higher latitude will make this volume shrinkage only stronger. That permanent generation of extra mass in tropical atmosphere causes concentration of vapor mass at tropics is about $2 \%$ higher than that at higher latitudes, causing approximately the same degree drop in air pressure at higher latitudes; which in turn causes tropical air mass expansion and transmission to higher latitudes in both North and South directions. In northern hemisphere, this air transport to the cold North is causing extra precipitations with essential shrinkage of vapor and further contributing to air mass transport to higher latitudes. In mid-latitudes those transmissions will be knocked out to the east by rapidly increasing Coriolis force. This effect is causing strong atmospheric current at mid-latitudes in the east direction (jet stream). Jet streams are typically meandering from west to east, often traveling meridionally a very winding path with ridges and troughs. During major cold outbreaks over the USA, the jet stream often dives southstaying above the warm-cold boundary_-sometimes moving well over the Gulf of Mexico, displaying a typical "V" shape (Figure 4).

We also found that in the summer time water vapor generation is weak at the east cold side of the Pacific Ocean [15], this is making opportunity to close clockwise transport in the North Pacific. North American continent is facing downwards transport at the west coast of cold and dry air, and upwards transport of warm and humid air at Atlantic. This will cause fluctuation of eastwards jet stream current to the South over American continent and enhance strong mechanism of energy exchange between warm and cold air mass. This effect is enhanced by very low tropical vapor transport to the North over continental areas of Mexico. But cold and dry air of "V" shape jet stream from the North is making "synoptic explosions" when it approach warm water vapors of Gulf of Mexico. Last few decades vapor transport to North Pacific and North Atlantic is essentially increased [15] [27], which is inevitably enhancing mechanisms described above. Directions of long term changes in patterns described above will cause further intensifications in extreme weather effects, including tornadoes.

Jet stream has been believed to be associated with tornado outbreaks [13] [16] [17]. Using surface, upper-air, radar, and satellite data, Corfidi and his colleagues found that jet stream not only facilitated to set the stage for the initiation of the severe tornado outbreak on 3 - 4 April 1974, but also significantly contributed to its intensity, longevity and extent after tornado onset [13]. The evidence for the risks of jet stream for tornado development is 


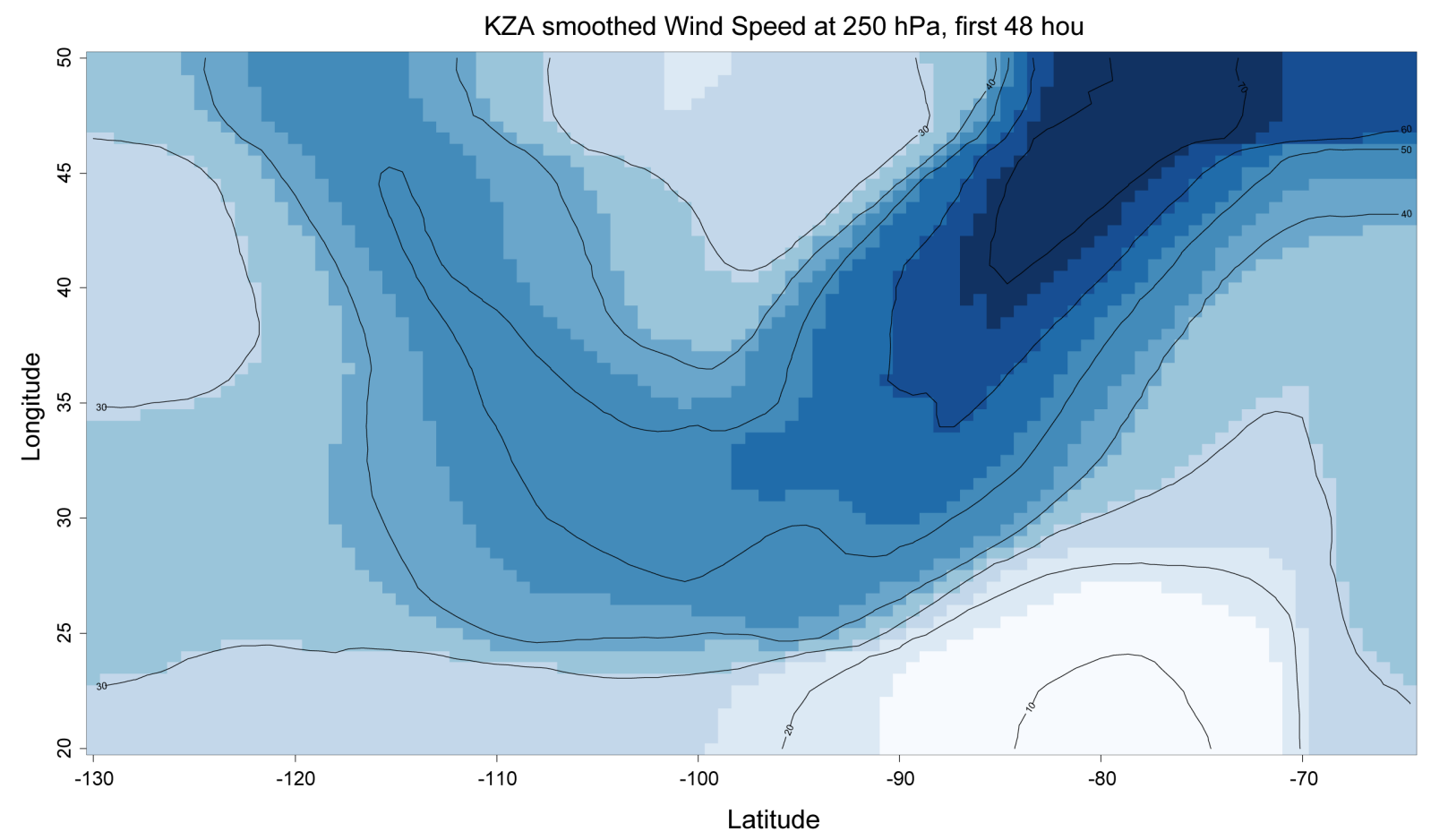

Figure 4. Displaying jet stream trajectory-a typical "V" shape over the USA during winter time.

inclusive, however. For example, we only viewed weather experts' claims, explanations for individual tornado cases, and medium reports [18] [19]; but there has been lack of a clear numerical support to evidence their relations between tornado development and jet streams. In this study, we are using the Modern-Era Retrospective Analysis for Research and Applications (MERRA) reanalysis data, to directly address patterns at a large scale. Such big scale can be understood only in a global level picture; available global information is not providing complete synoptic scale. But our 3D KZA filtering technology can reproduce global scales from existed information. We will examine the prevailing features of jet streams, especially in the months with high or relatively high tornado frequency, and study their associations with tornado risks.

\section{Data Source}

To investigate if and how jet stream associate to tornado development in the USA, we used hourly reanalysisdata "tavg1_2d_slv_Nx", from The Modern Era Retrospective-analysis for Research and Applications, National Aeronautics and Space Administration (MERRA/NASA). Hourly averages of zonal and meridional ( $u$ and $v$ respectively) wind velocity components were available at $0.66667 \times 0.5$ degrees horizontal resolution and with 3 vertical levels at 250, 500 and $850 \mathrm{hPa}$. MERRA covers the period 1979-present, continuing as an ongoing climate analysis as resources allow. As a pioneer study, this study will focus only on the period 1979-1988, at the vertical level of $250 \mathrm{hPa}$ over USA.

Tornadodata (1950-2012) is available online from the Storm Prediction Center, NOAA's National Weather Service (http://www.spc.noaa.gov/wcm/\#data). National Weather Service provides comma separated value (.csv) files for tornado, hail, and damaging wind data as compiled from NWS Storm Data. Tornado reports exist back to 1950 while hail and damaging wind reports date from 1955. Given that MERRA data are available from 1979, we will only focus on the period 1979-1988.

\section{Methods}

In north hemisphere, the jet streams are located between the 400 and the $100 \mathrm{hPa}$ levels [20]. With substantial variations in wind speed and elevation, jet streams are not continuous, they can break off at times and merge again "downstream" eventually; this makes it ambiguous and difficult to clearly identify jet stream's wind speed 
and boundaries at a given time [21]. Whereas, jet streams are located near the tropopause, air pressure $p$ can be used to characterize the height of both the jet streams and the tropopause [20]. Therefore, we define the wind speed at $250 \mathrm{hPa}$ as the jet stream at any given location and time in this study:

$$
\mathrm{WS}=\sqrt{u^{2}+v^{2}}
$$

where WS is the actual wind speed of jet stream at given time and location, $u$ is the eastward wind speed $(\mathrm{m} / \mathrm{s})$ at $250 \mathrm{hPa}, v$ is the northward wind speed $(\mathrm{m} / \mathrm{s})$ at $250 \mathrm{hPa}$.

Applying KZ Adaptive (KZA) filter [22] [23], we smoothed jet streams over USA and compared their distribution between tornado days and non-tornado days. A computer algorithm implementing KZA filter is available in R-software [24].

Let $X(t), t=0, \pm 1, \pm 2, \cdots$, be a real valued time series. Firstly, we can write KZ filter's mathematical form $\mathrm{KZ}_{(q, k)}$ as

$$
Z(t)=\mathrm{KZ}_{q, k}[X(t)]=\frac{1}{2 q+1} \sum_{s=-q}^{q} X(t+s)
$$

where $X$ is the input time series, parameter $q$ is half length of the moving average window and $\mathrm{k}$ is the number of iterations. The data series $Z(t)$ becomes the input series for the second iteration, and so on.

We define the absolute change within the $\mathrm{KZ}$ window as $D(t)=|Z(t+q)-Z(t-q)|$, and the rate of absolute change as $D^{\prime}(t)=D(t+1)-D(t)$.

The fundamental logic of the KZA filter is to reconstruct the length of the moving average window before ( $q H$-head of the moving average window) and after ( $q T$ - tail of the moving average window) the smoothing point separately: while the smoothing point arrives at time intervals where $D(t)$ increases $\left(D^{\prime}(t)>0\right), q H$ is shortened as a function of $D(t)$ and $q T$ is unchanged; whereas the smoothing point arrives at time intervals where $D(t)$ decreases $\left(D^{\prime}(t)<0\right)$, qT is shortened as a function of $D(t)$ and $q H$ is unchanged. Thus, in the vicinity of an abrupt-turning point, the moving average window is reduced and the resolution of the smoothed result increased accordingly. Formally, the KZA is defined as

$$
Y^{(k)}(t)=\frac{1}{q T(t)+q H(t)+1} \sum_{s=-q T(t)}^{q H(t)} Y^{(k-1)}(t+s)
$$

where

$$
\begin{gathered}
q T(t)=\left\{\begin{array}{lr}
q, & D^{\prime}(t)>0 \\
f(D(t)) q, D^{\prime}(t) \leq 0
\end{array}\right. \\
q H(t)=\left\{\begin{array}{lr}
q, & D^{\prime}(t)<0 \\
f(D(t)) q, D^{\prime}(t) \geq 0
\end{array}\right. \\
f(D(t))=1-\frac{D(t)}{\operatorname{Max}(D(t))}
\end{gathered}
$$

Simulation studies showed that KZA filter performs well in both one-dimensional and high-dimensional data [23] [25] [26]. Zurbenko et al. showed that KZA filter is an exploratory non-parametric method exploring "break" locations more precisely in the presence of seasonal patterns [22]-[26]. In this study, we will use KZA filter to smooth/reconstruct 3-dimensional signal of jet stream, with a three dimensional moving average window: $(x, y, t)=(5,5,3)$. The jet stream data (wind speed) were embedded in a three dimensional array and can be represented as $S(x, y, t)$; where $t$ is discrete hourly time and $(x, y)$ is the spatial coordinates at $0.66667 \times 0.5$ degrees horizontal resolution. As applying KZA filter, a spatial moving average filter was first applied over $5 \times$ 5 cells of the grid with three iterations. As a result, adjacent fluctuation (short-term) was smoothed within each cell $(x, y)$. Secondly, a temporal filter with a three-hour window was then applied across each cell $(x, y)$ three times. The whole process is essentially to apply a three dimensional KZA filter over $T(x, y, t)$ in both time and spatial domain. 


\section{Results and Findings}

\subsection{Trends and Geographical Distributions of Tornado Outbreaks}

A total of 8306 tornadoes with valid date and location of occurrence in the United States from 1979 through 1988 were identified. Geographic distribution of overall tornado onsets displayed a violent turbulence in the number of tornadoes across the country (Figure 5). The geographic areas (at state level) most commonly hit by tornadoes were displayed in dark-blue or blue, depends on the frequency of tornado occurrence. All states except for 8 states were hit by tornadoes less than 300 times during the time period studied. Texas experienced the most, with 1413 tornadoes; followed by Florida with 573 tornadoes, Oklahoma with 520 tornadoes and Iowa with 406 tornadoes. The other 4 states experiencing more than 300 tornadoes were Colorado with 351 tornadoes, Kansas with 341 tornadoes, Nebraska with 331 tornadoes and South Dakota with 323 tornadoes.

Tornado occurrence not only showed geographic preference, it conferred temporal variation as well. Figure 6 below showed the fluctuation trend at the quarter (3 months) scale. Basically all the four statistics, quarterly tornado sum, minimum, maximum and mean of monthly tornado counts showed the very similar pattern across the study time period. However, tornado outbreaks were not distributed evenly around the year, for each year, the majority tornadoes occurred in the second quarter. Overall we may see a drop of tornado frequency after 1985; but the study period is relative short to make such a conclusion.

\subsection{Monthly, Hourly, Latitude and Longitude Distribution}

Although tornadoes occurred at any time anywhere of the world, tornadoes developed in the United States from 1979 through 1988 displayed a clear seasonality addressed above. While looking at the monthly tornado frequency over the study period, the probability of developing tornadoes was dramatically high in May and June (Figure 7). In general, about half tornadoes occurred in May (22.83\%, 1896 out of 8306) and June (19.62\%, 1630 out of 8306$)$; but less than $5 \%$ of tornadoes happened to occur in January $(0.96 \%$, 80 out of 8306 ) and February $(2.06 \%, 251$ out of 8306). To help better understand the patterns of tornado development complications on a more detailed level, hourly tornado frequency was calculated on a diurnal scale (Figure 8).

Despite the dramatic variations in tornado frequency between months, the pattern of tornado occurrence demonstrated a uniform feature on a diurnal scale. No matter in which month, the majority of tornadoes developed in the afternoon and evening hours between 2:30 PM and 8:00 PM. To closely investigate the geographic distribution of tornado outbreaks, we demonstrated longitudinal (Figure 9) and latitudinal (Figure 10) tornado frequency in March, April, May, June, July and August, in which the tornado risks were very high or relatively high. We intended to look for any prevailing patterns behind these unpredictable tornado onsets.

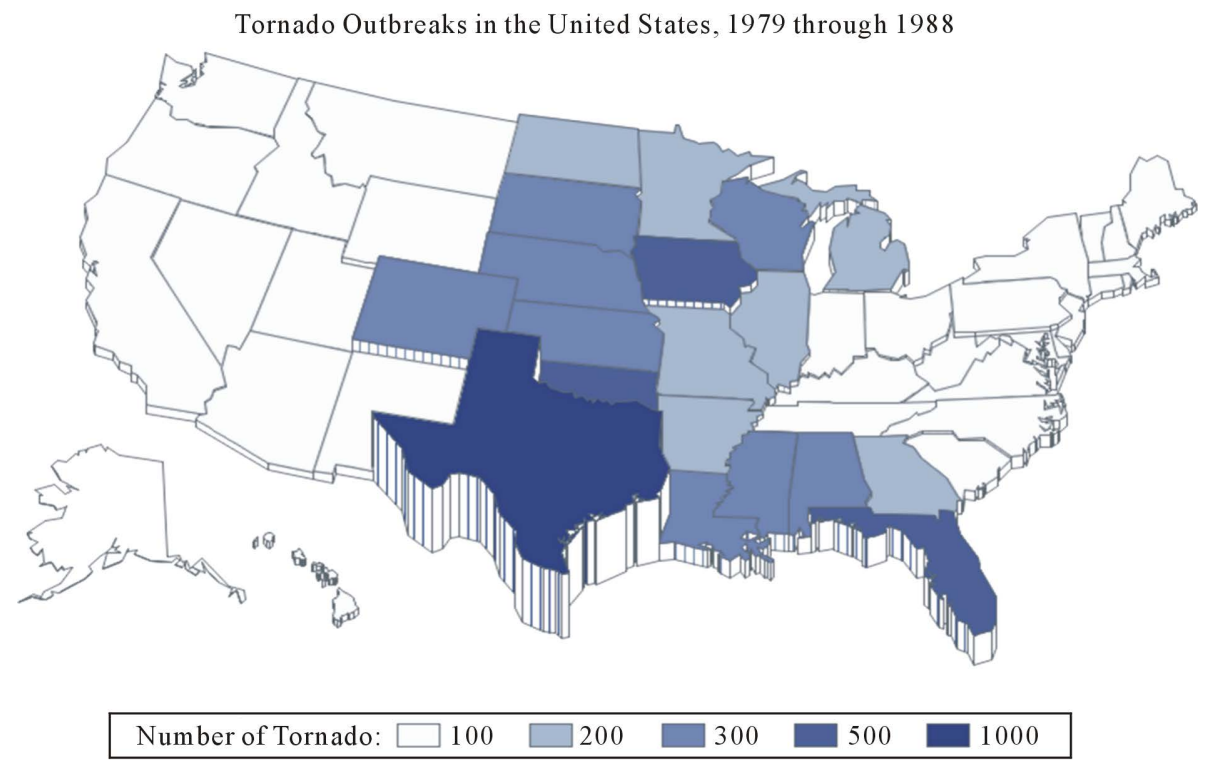

Figure 5. Geographic distribution of tornado outbreaks in U.S., from 1979 through 1988. 
Trend of Tornado Occurrence, 1979-1988

Monthly Tornado Counts by Quart - Max (blue), Min (green), Mean (red) and Sum (black dot)

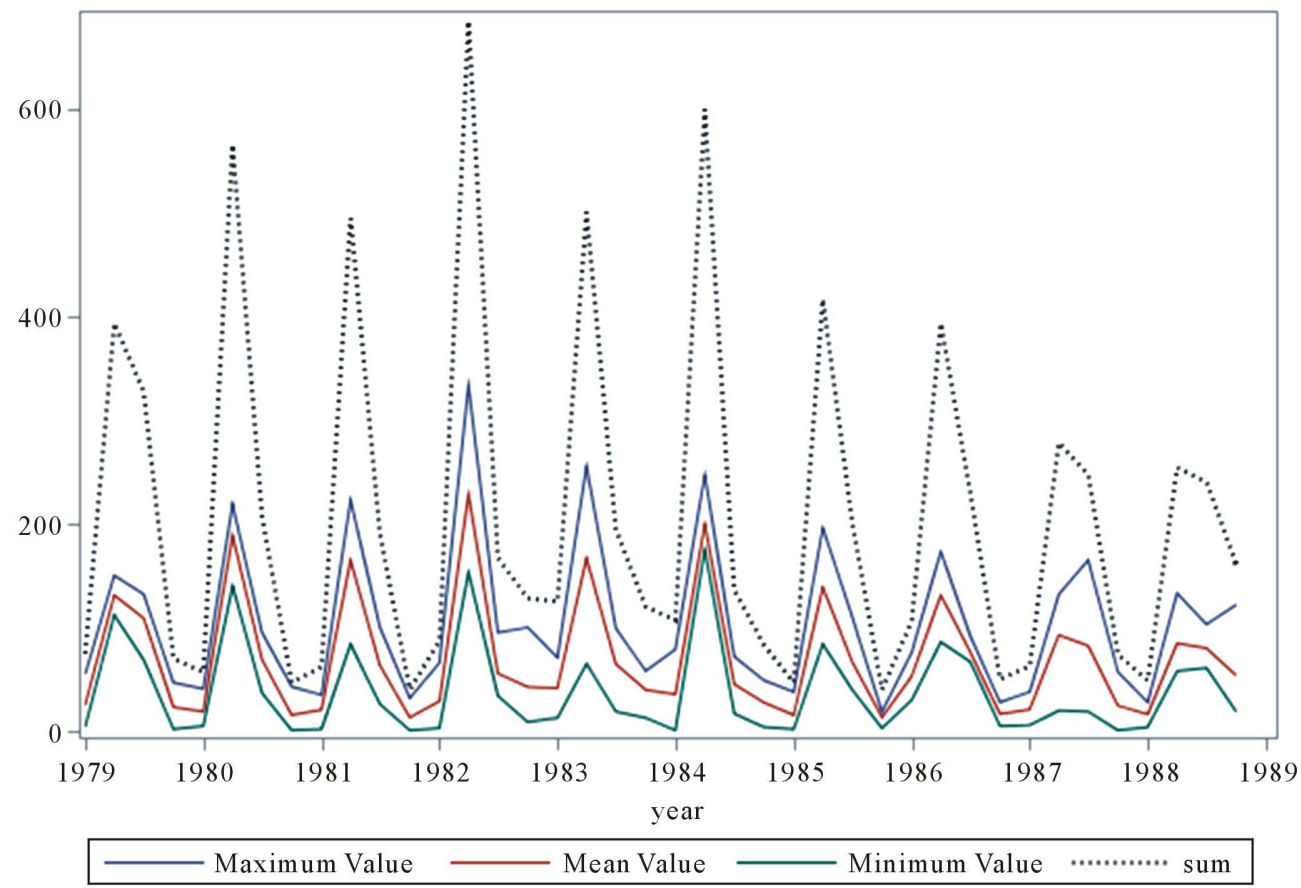

Figure 6. Trends of tornado frequency by quarter, from 1979 through 1988.

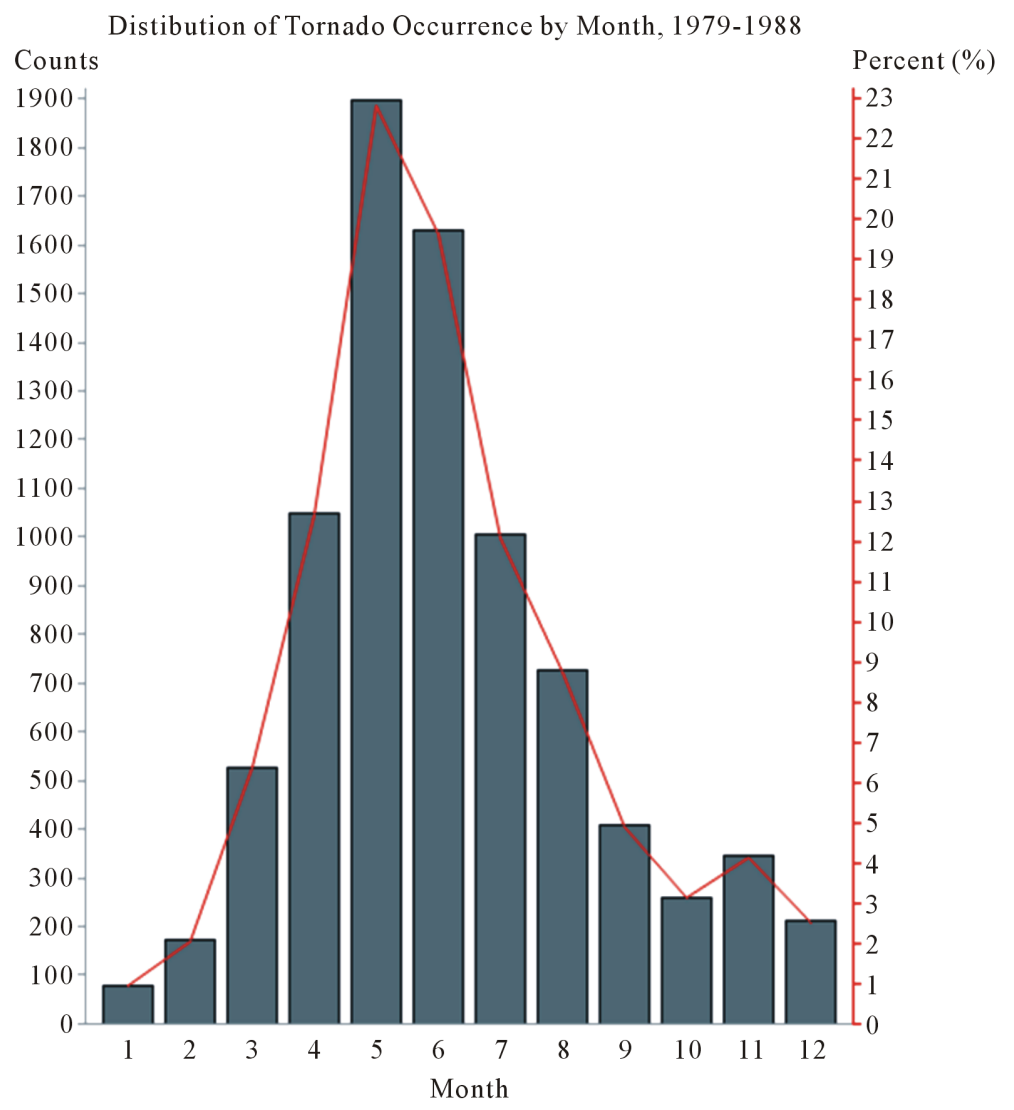

Figure 7. Tornado frequency by month, from 1979 through 1988. 


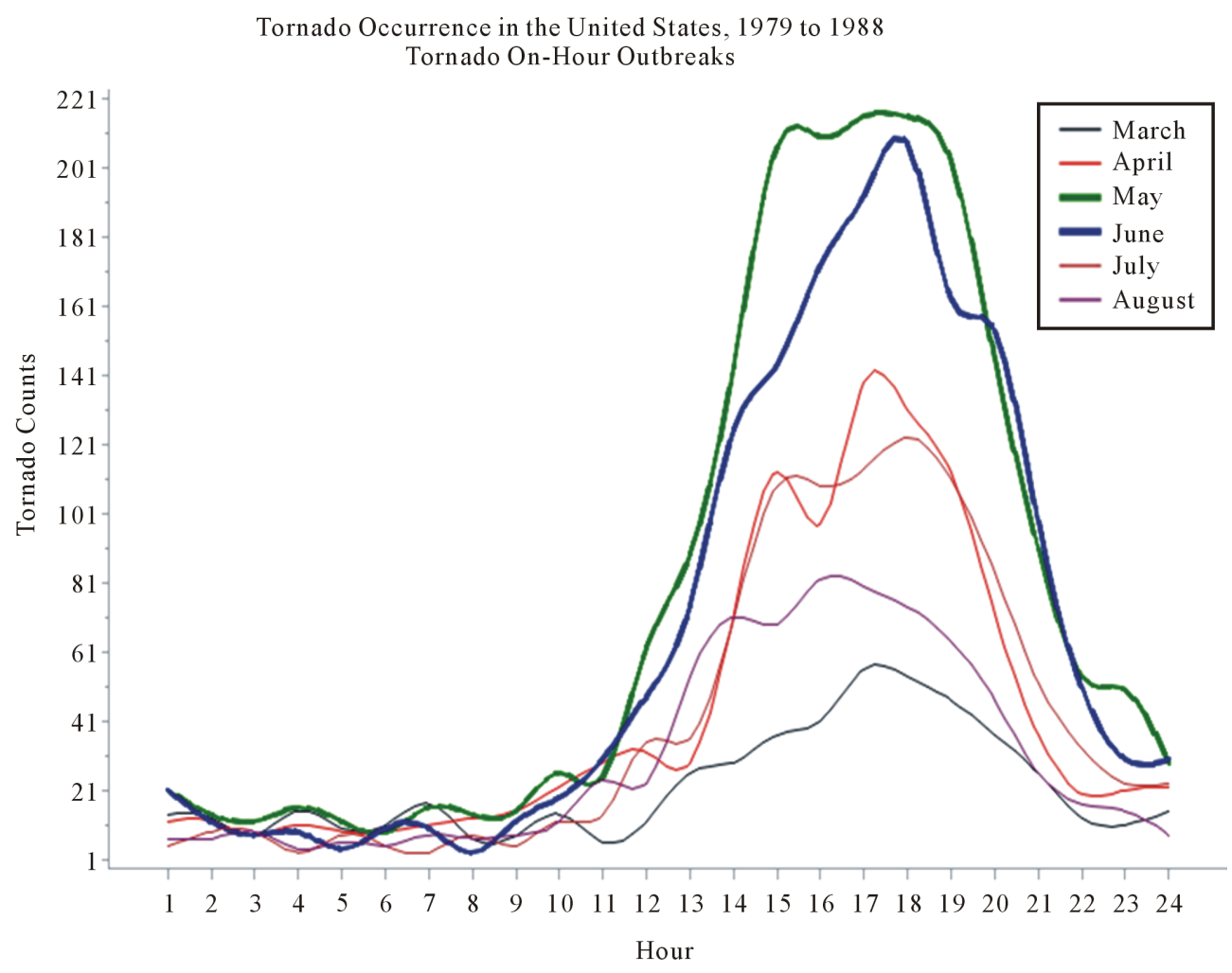

Figure 8. Hourly tornado frequency in selected month, from 1979 through 1988.

Tornado Occurrence in the United States, 1979 to 1988

Moving-Average Smoothed Plot of Tornado Outbreaks by Longitudes

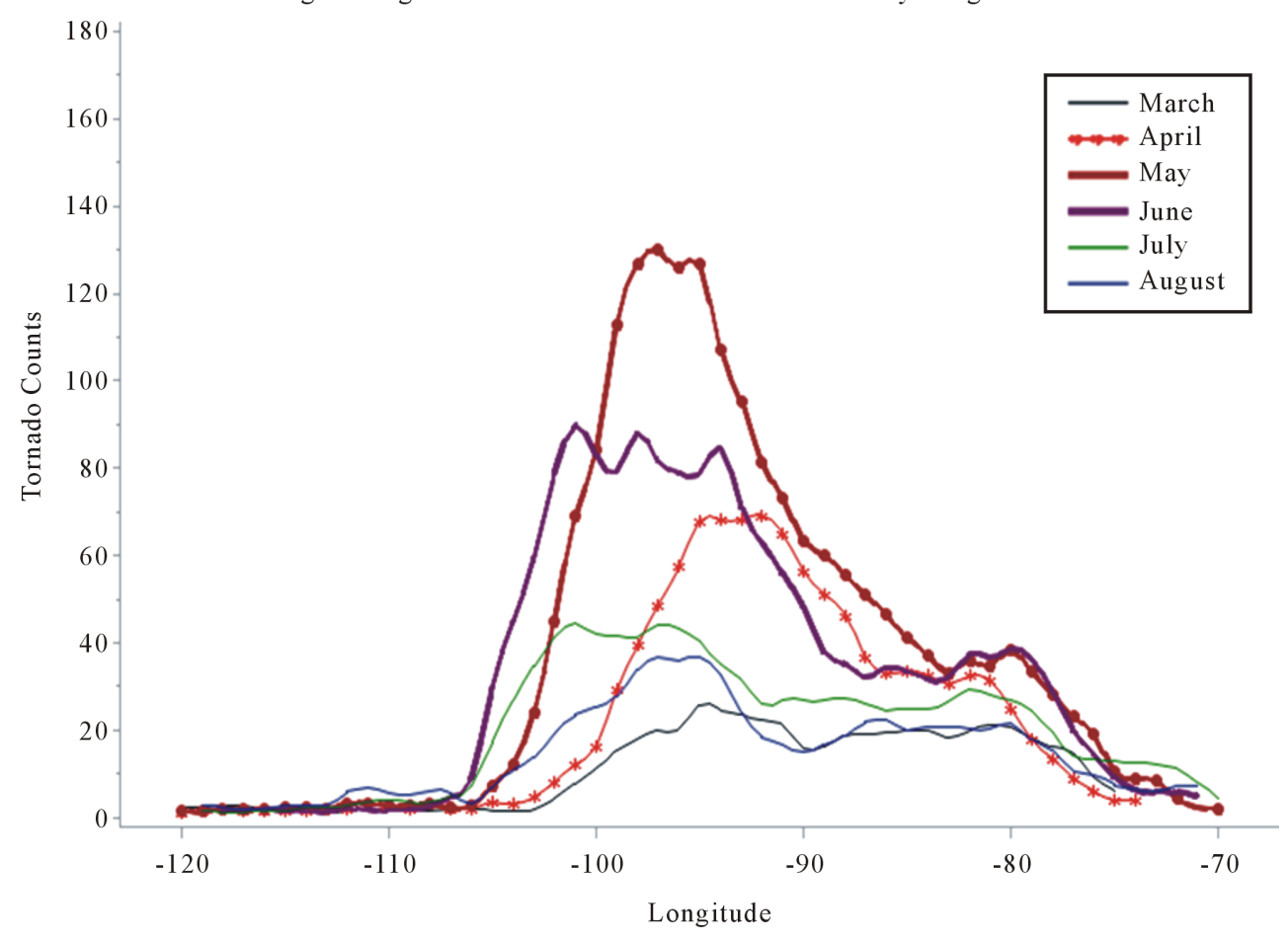

Figure 9. Longitudinal distribution of smoothed tornado frequency in selected month, from 1979 through 1988. 


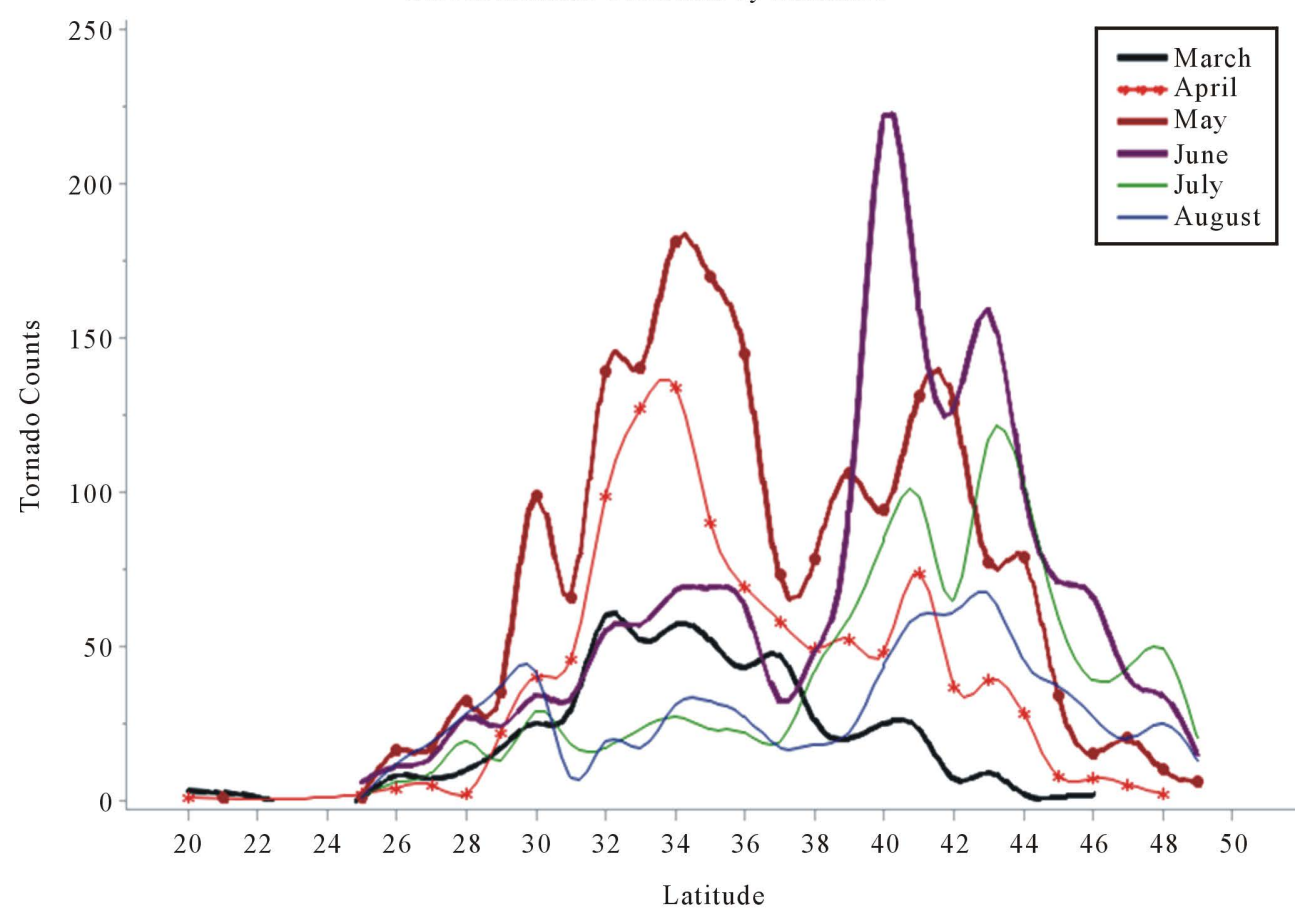

Figure 10. Latitudinal distribution of tornado frequency in selected month, from 1979 to 1988.

Smoothed tornado frequency with moving average (window size equals to five), showed a different pattern at the longitudinal scale for different month. Except for March and August with only one modest peak located at $95^{\circ} \mathrm{W}$, number of tornadoes developed in each month, from April through July, more or less displayed two peaks. One peak was dominant located at $98^{\circ} \mathrm{W}$, and its width covered about 10 degree of longitudinal zones from west to east; another peak was much more modest, located near $80^{\circ} \mathrm{W}$. This pattern is a perfect reflection of tornadoes' geographic distribution showed in Figure 5. The dominant peak reflected the major tornado frequency in "tornado alley" area; and the modest peak witnessed the explicit high tornado frequency in Florida State.

Risks of tornado occurrence in the USA displayed a very clear latitude-month shifting pattern, with the most tornados developed in April, May and June (Figure 10), at lower latitudes first and higher latitudes later. A delayed effect of tornado development was obviously seen along with the latitudes rising. Another word, while the Mother Nature was going from March all the way through summer, to August, peak of tornado outbreaks was meandering from south to north across the mid latitudes in the United States. The tornado frequency in March and April peaked near $34^{\circ} \mathrm{N}$, in July and August around $42^{\circ} \mathrm{N}$, and in May and June with double peaks near $34^{\circ} \mathrm{N}$ and $42^{\circ} \mathrm{N}$ respectively. This prevailing feature of tornados coming later at higher latitudes was seen concurrently oscillated with monthly distribution of daily wind maxima in April, May and June, in our previous study [27]. Aiming to ensure the potential relationship between jet stream and tornado development, we will calculate jet stream distribution directly, rather than distribution of maximum wind speed.

\subsection{Monthly Trends and Spatial Distributions of Jet Streams}

We extracted the hourly eastward and northward wind speed at $250 \mathrm{hPa}$ from MERRA's 3D reanalysis database for each grid at the available horizontal resolution, for the period of 1979 to 1988 . A 10-year 3D hourly time series of wind speed, hereafter referred to as the jet stream, was calculated for each grid. After applying KZA filter to the jet stream time series, monthly contour map of the smoothed jet stream were plotted in Figure 11.

Figure 11 shows average jet stream (blue) to the region of East America, over North Carolina area in January and February; to the Gulf of Mexico region, ranging from $110^{\circ} \mathrm{W}$ to $70^{\circ} \mathrm{W}$ and $23^{\circ} \mathrm{N}$ to $35^{\circ} \mathrm{N}$ in March and April; by the time of May, jet stream was not consistently hovering, rather sparklingly scattering over the Gulf of Mexico region. From June, through July, August and September, jet stream was meandering over the region of 

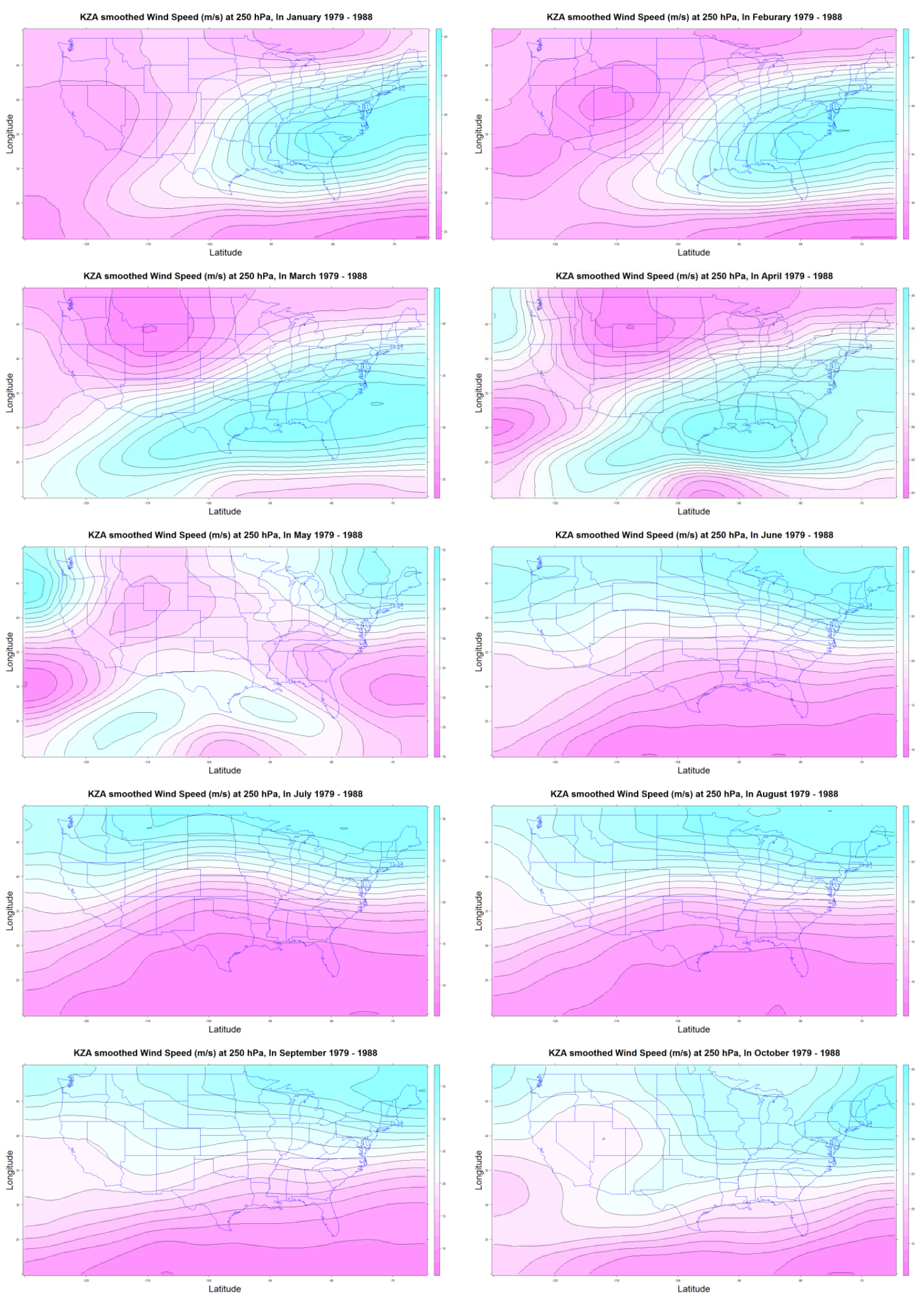

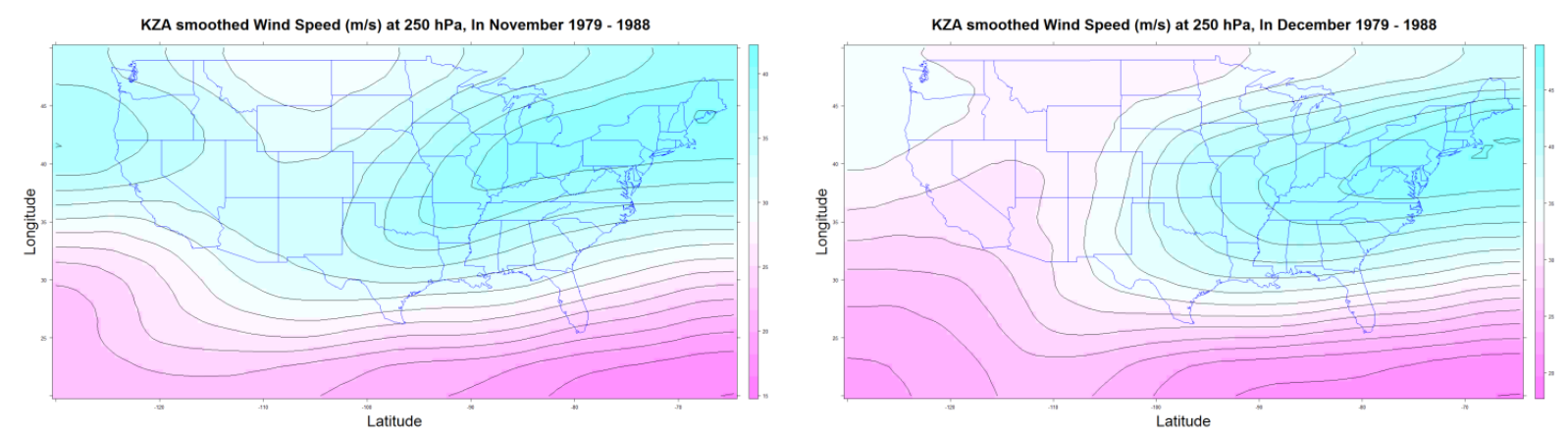

Figure 11. Spatial distribution of jet stream by month.

USA beyond $35^{\circ} \mathrm{N}$; jet stream started to move towards south from Maine State area in October, gradually to the region of North-east America, over New York State in November, and back to the region of East America over Virginia area in December. Monthly trends and geographic distribution patterns of jest stream were substantial and clear: jet stream at $250 \mathrm{hPa}$ reached to south in winter (January, February and December) and spring (March, April and May); but it shifts northward back in summer (June, July and August) and autumn (September, October and November). It is very interesting that jet streams were meandering over the Gulf of Mexican area in spring, which is the pike time around year for tornado to develop in south of tornado alley, such as Texas [7]. While jet stream was moving from Gulf of Mexican region in spring to the mid latitudes in summer, peaks of tornado frequency shifted parallel from low latitudes to higher latitudes (Figure 10). A consensus has emerged in viewing this consistence between tornado outbreaks and the trajectory jet stream traveled. This suggests an association of jet stream with tornado development.

\subsection{Diurnal Distribution of Top 3 Daily Maximum Wind Speed and Tornado Occurrence}

Using hourly MERRA data, we calculate the daily maximum wind speed $\left(\mathrm{WS}_{\max }\right)$ for each grid at $0.66667 \times 0.5$ degrees horizontal resolution, ranging from $130^{\circ} \mathrm{W}$ to $65^{\circ} \mathrm{W}$ and $20^{\circ} \mathrm{N}$ to $50^{\circ} \mathrm{N}$. After generating the $3 \mathrm{D}$ matrix of $\mathrm{WS}_{\max }$ at $250 \mathrm{hPa}$ for the period of 1979 to 1988, diurnal distribution of $\mathrm{WS}_{\max }$ was calculated. Both diurnal average of top 3 daily $\mathrm{WS}_{\max }$ and hourly distribution of tornado risks (probability) were displayed in Figure 12. An impressive relationship between tornado onsets and top 3 daily maximum wind speed was observed. Diurnal distribution of daily top $3 \mathrm{WS}_{\max }$ and risk for tornado occurrence showed a fairly strong positive correlation of 0.73. Risks for tornado occurrence started to increase from noon, peaked at 4 and/or 5 PM in the late afternoon; synchronously, daily maximum wind speed of jet stream saw a similar pattern, with the most number of daily $\mathrm{WS}_{\max }$ appeared at $5 \mathrm{PM}$. This can be explained by the time delay effect of temperature in response to sun radiation (Figure 13). Jet stream is originally driven by water vapor created in tropical area [27]. This mechanism depends completely on amount of provided sun radiation, which is stronger in a day time and maximum cumulative effect will not be reached until late of the day. So by which time in average it provide strongest speed in jet stream, which in turn affect all atmospheric processes including extreme weather events like tornados as we observed in this study.

\subsection{Comparisons of Jet Stream Spatial Distribution between Tornado Days and Non-Tornado Days in May}

Given May experienced the highest number of tornados from 1979 through 1988 (Figure 7), we select these days in May, on which no single tornado was ever developed as non-tornado days (in blue in Table 1); select about the same number of other days in May, on which many tornadoes were developed as tornado days (in red in Table 1). We intended to compare the spatial distribution of jet stream between tornado days and non-tornado days. To have a more precise comparison, we also stratified the entire month as 3 time periods: beginning, middle and end of May.

To look at the geographic distribution of jet stream on tornado days in May, we smoothed the wind speed at $250 \mathrm{hPa}$ by using $\mathrm{KZA}_{(\mathrm{c}(5,5,3), \mathrm{k}=3)}$ filter. We observed a quasi-V shape trajectory jet stream traveled in May on tornado days, with the highest wind speed (35 meters per second) dominantly located over the region of Gulf of 
I. G. Zurbenko, M. Z. Sun

Table 1. Tornado counts in may, from 1979 through 1988 ( $\mathrm{N}=1896)$.

\begin{tabular}{|c|c|c|c|c|c|c|c|c|c|c|c|}
\hline \multirow{2}{*}{ Period } & \multirow{2}{*}{ Day } & \multicolumn{10}{|c|}{ Tornado Counts } \\
\hline & & 1979 & 1980 & 1981 & 1982 & 1983 & 1984 & 1985 & 1986 & 1987 & 1988 \\
\hline \multirow{10}{*}{ Beginning } & 1 & 6 & 6 & 1 & 0 & 37 & 4 & 4 & 1 & 1 & 0 \\
\hline & 2 & 9 & 0 & 0 & 0 & 21 & 24 & 3 & 0 & 1 & 8 \\
\hline & 3 & 25 & 0 & 3 & 2 & 2 & 40 & 1 & 0 & 5 & 1 \\
\hline & 4 & 4 & 0 & 1 & 4 & 0 & 2 & 2 & 2 & 0 & 0 \\
\hline & 5 & 2 & 2 & 0 & 7 & 4 & 2 & 0 & 0 & 1 & 0 \\
\hline & 6 & 0 & 7 & 3 & 6 & 6 & 8 & 3 & 2 & 0 & 3 \\
\hline & 7 & 0 & 2 & 12 & 6 & 0 & 26 & 1 & 9 & 1 & 5 \\
\hline & 8 & 21 & 3 & 5 & 0 & 0 & 14 & 3 & 13 & 0 & 58 \\
\hline & 9 & 2 & 3 & 18 & 7 & 0 & 0 & 0 & 10 & 0 & 2 \\
\hline & 10 & 3 & 0 & 1 & 5 & 2 & 0 & 18 & 9 & 1 & 2 \\
\hline \multirow{10}{*}{ Middle } & 11 & 2 & 2 & 4 & 36 & 0 & 0 & 24 & 6 & 0 & 1 \\
\hline & 12 & 0 & 11 & 0 & 35 & 8 & 5 & 3 & 4 & 2 & 1 \\
\hline & 13 & 0 & 4 & 13 & 13 & 31 & 0 & 14 & 10 & 3 & 0 \\
\hline & 14 & 1 & 1 & 0 & 15 & 7 & 2 & 4 & 20 & 1 & 0 \\
\hline & 15 & 2 & 12 & 7 & 18 & 1 & 1 & 2 & 24 & 0 & 3 \\
\hline & 16 & 0 & 3 & 11 & 15 & 12 & 2 & 1 & 32 & 1 & 2 \\
\hline & 17 & 1 & 10 & 20 & 19 & 11 & 0 & 0 & 10 & 6 & 1 \\
\hline & 18 & 1 & 1 & 9 & 9 & 19 & 14 & 1 & 3 & 4 & 1 \\
\hline & 19 & 0 & 7 & 0 & 19 & 18 & 3 & 2 & 2 & 10 & 4 \\
\hline & 20 & 5 & 14 & 3 & 19 & 29 & 1 & 11 & 3 & 4 & 5 \\
\hline \multirow{11}{*}{ End } & 21 & 4 & 0 & 0 & 5 & 13 & 5 & 6 & 2 & 2 & 7 \\
\hline & 22 & 4 & 0 & 14 & 2 & 6 & 1 & 2 & 0 & 4 & 2 \\
\hline & 23 & 1 & 3 & 29 & 4 & 4 & 2 & 3 & 0 & 1 & 2 \\
\hline & 24 & 5 & 6 & 10 & 8 & 1 & 5 & 2 & 4 & 5 & 3 \\
\hline & 25 & 0 & 16 & 2 & 4 & 2 & 2 & 3 & 0 & 23 & 0 \\
\hline & 26 & 2 & 9 & 6 & 6 & 1 & 1 & 5 & 1 & 14 & 0 \\
\hline & 27 & 3 & 7 & 3 & 18 & 11 & 2 & 7 & 2 & 8 & 3 \\
\hline & 28 & 2 & 15 & 6 & 17 & 1 & 1 & 7 & 1 & 7 & 2 \\
\hline & 29 & 3 & 42 & 2 & 12 & 3 & 1 & 5 & 1 & 11 & 2 \\
\hline & 30 & 4 & 10 & 0 & 17 & 3 & 1 & 19 & 1 & 5 & 12 \\
\hline & 31 & 0 & 10 & 4 & 5 & 2 & 6 & 40 & 1 & 5 & 3 \\
\hline
\end{tabular}




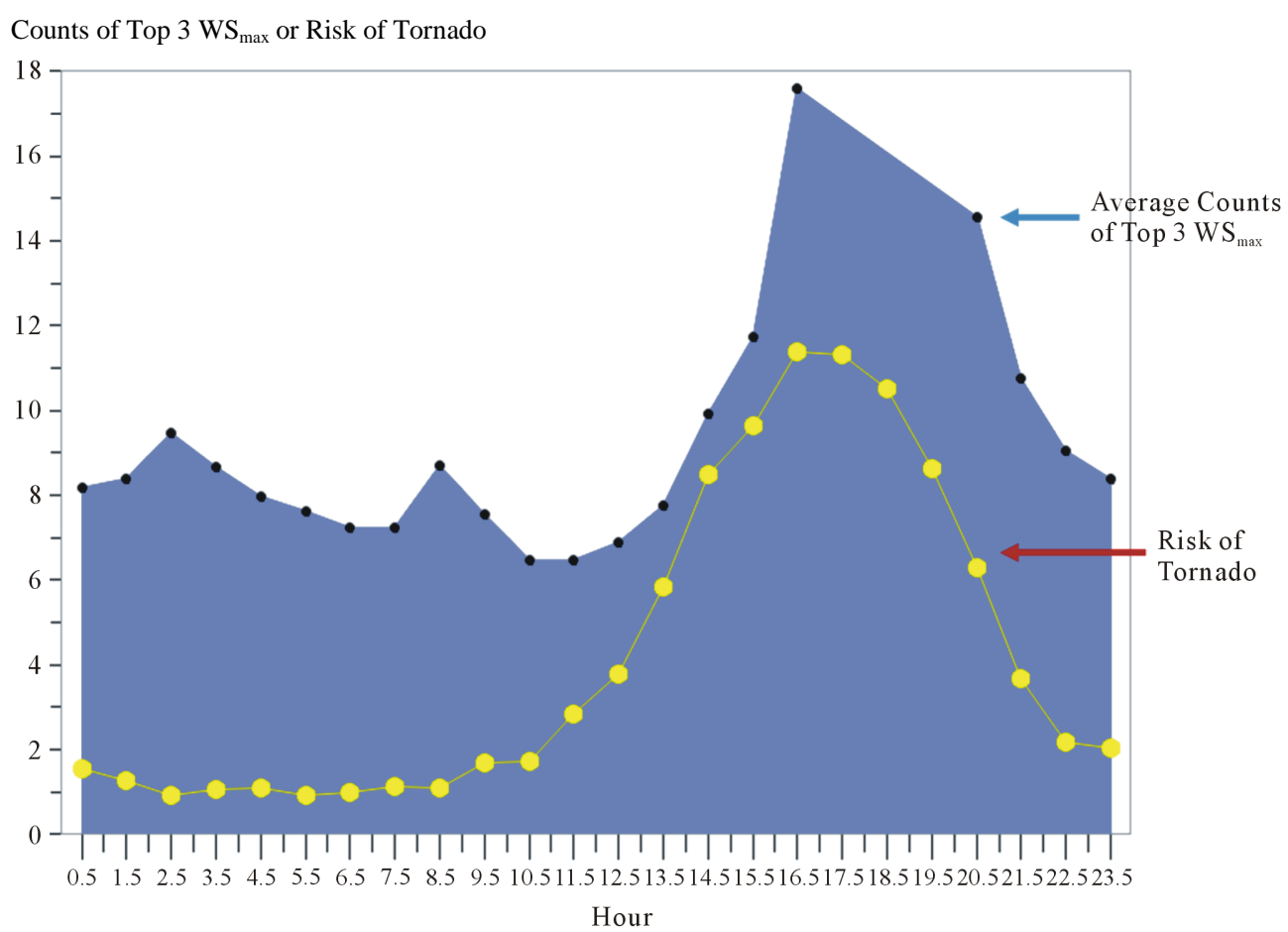

Figure 12. Diurnal distribution of daily top $3 \mathrm{WS}_{\max }$ and tornado occurrence.

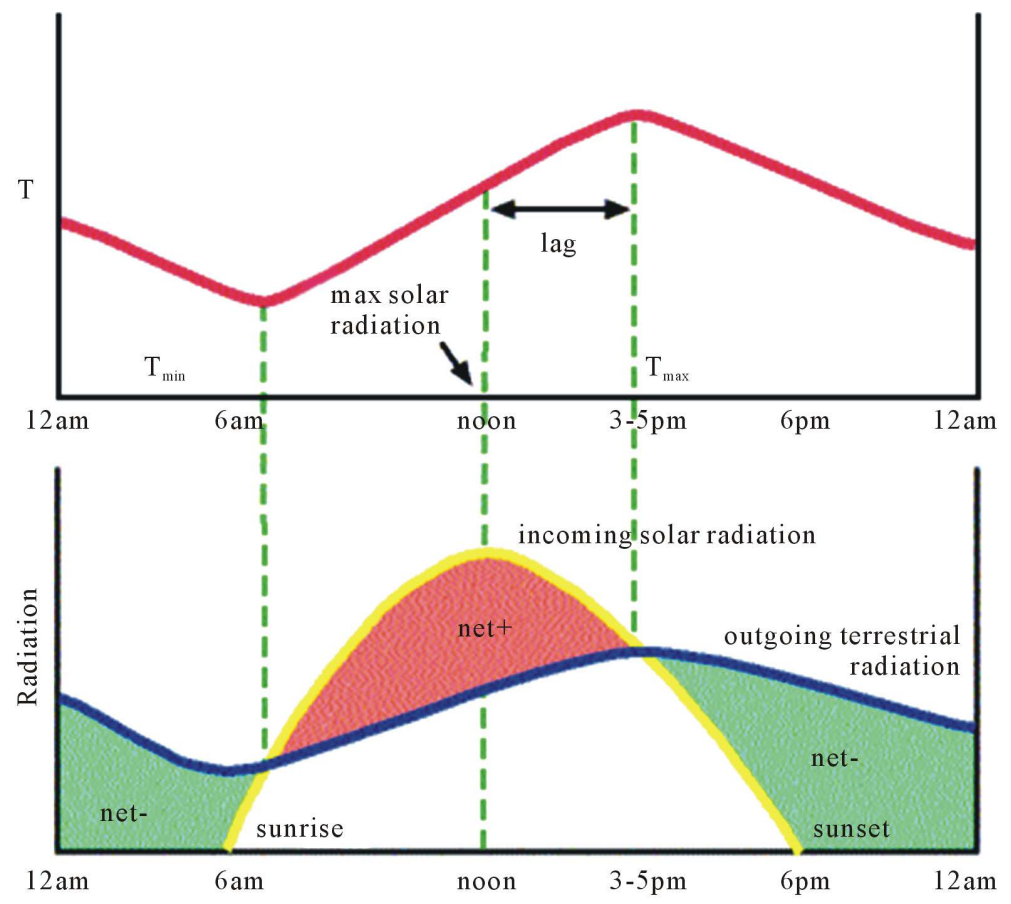

Figure 13. Daily temperature variations http://apollo.lsc.vsc.edu/classes/met130/notes/chapter3/daily_trend5.html

Mexican area; on the contrary, not only V shape trajectory, but even average wind speed of jet stream were not seen on non-tornado days over the Gulf of Mexican region. It was even more impressive that a lowest wind speed (20 meters per second) zone was observed over the Gulf of Mexican area (white part in Figure 14). This substantially demonstrated that jet stream associated with tornado outbreaks in May. 

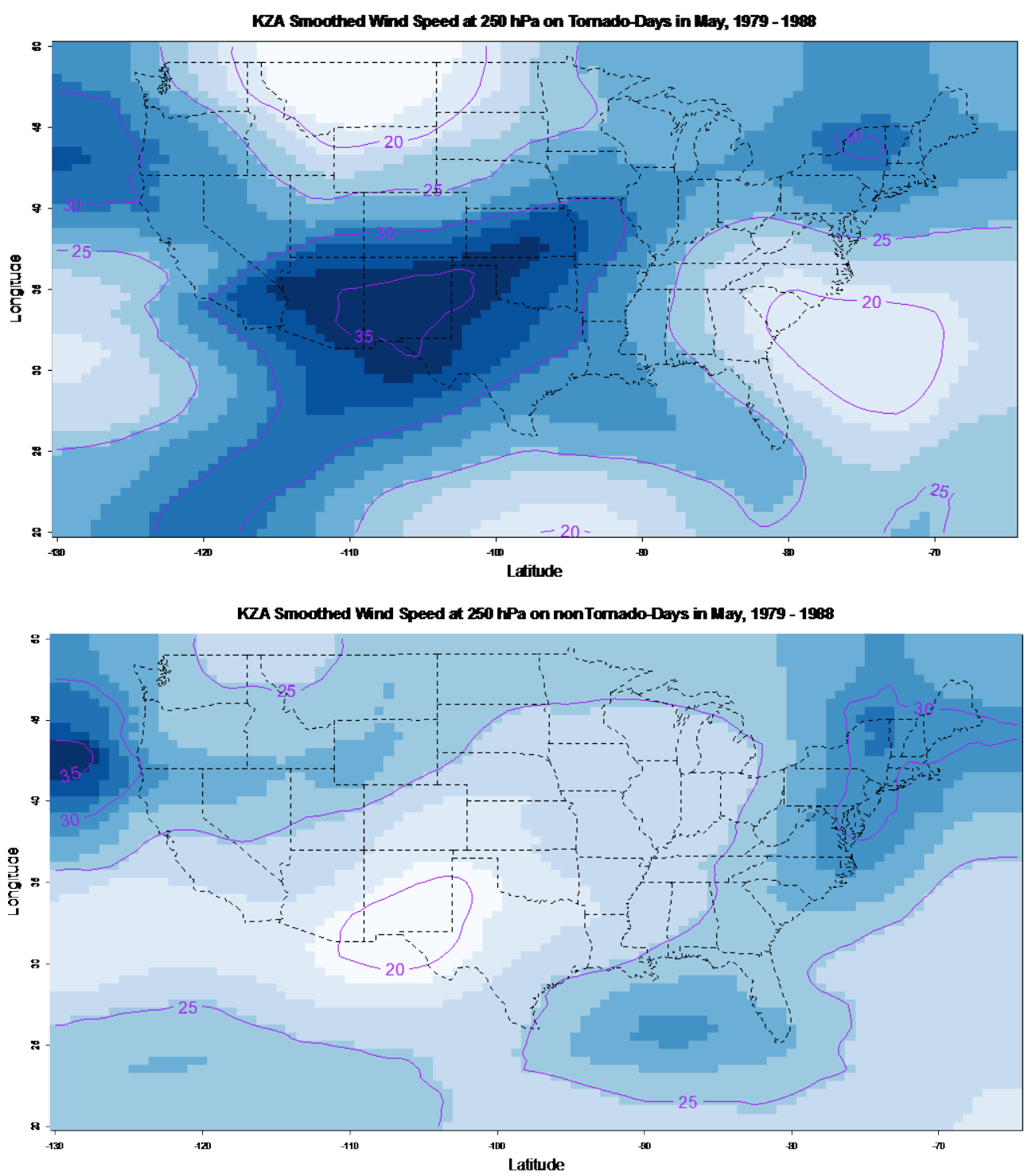

Figure 14. Geographic distribution of jet stream on tornado days and non-tornado days in May.

Given that jet stream's spatial distribution conferred an explicit timing/seasonal trend, we stratified the entire month as beginning (May 1 through May 10), middle (May 11 through May 20) and end (May 21 through May 31) three narrower time window to perform a more precise measure. Figure 15 displayed a consistent pattern across the three time window: on tornado days for all the three time periods in May, we observed high wind speed (35 to 45 meters per second; the dark blue area) of jet stream located over the Gulf of Mexican region, with a slightly shift towards west sometimes. This is exactly a reflection on the observations that more daily wind speed maxima appeared over the same region in our previous study [27]. In contrast, on non-tornado days in May, much lower wind speed (usually 20 meters per second) of jet stream was observed over the same latitudinal regions compared with tornado days. Thus jet stream facilitates to set the stage for tornado development; the strength of this background wind field increased the chance that a tornado would form any moment once other factors for tornado development available.

\section{Summary}

Geographic shift and timing variations of jet stream are expected to affect weather patterns by rapidly pushing weather systems from one area to another, and therefore strong energy exchange in the jet stream current is 

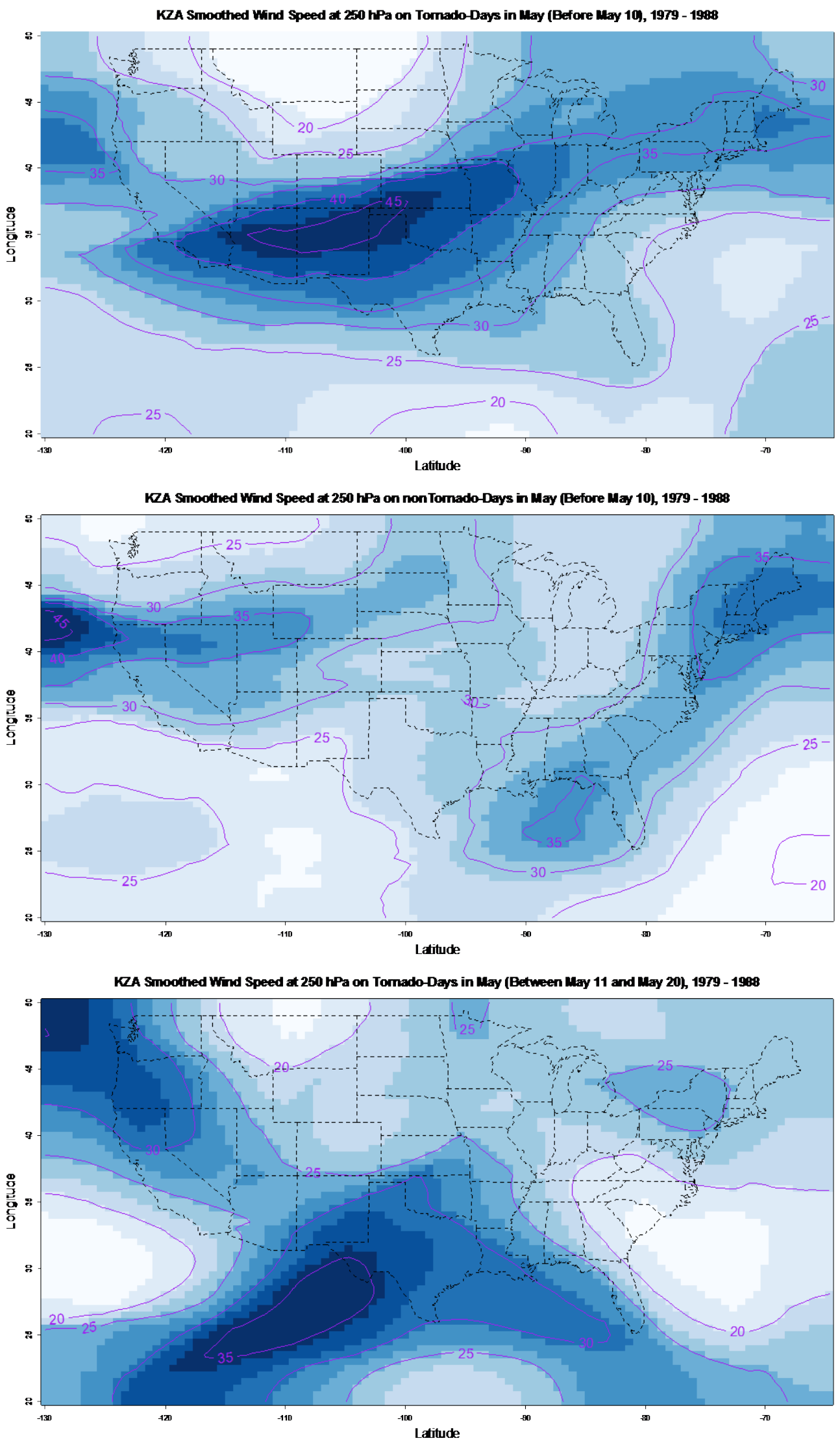


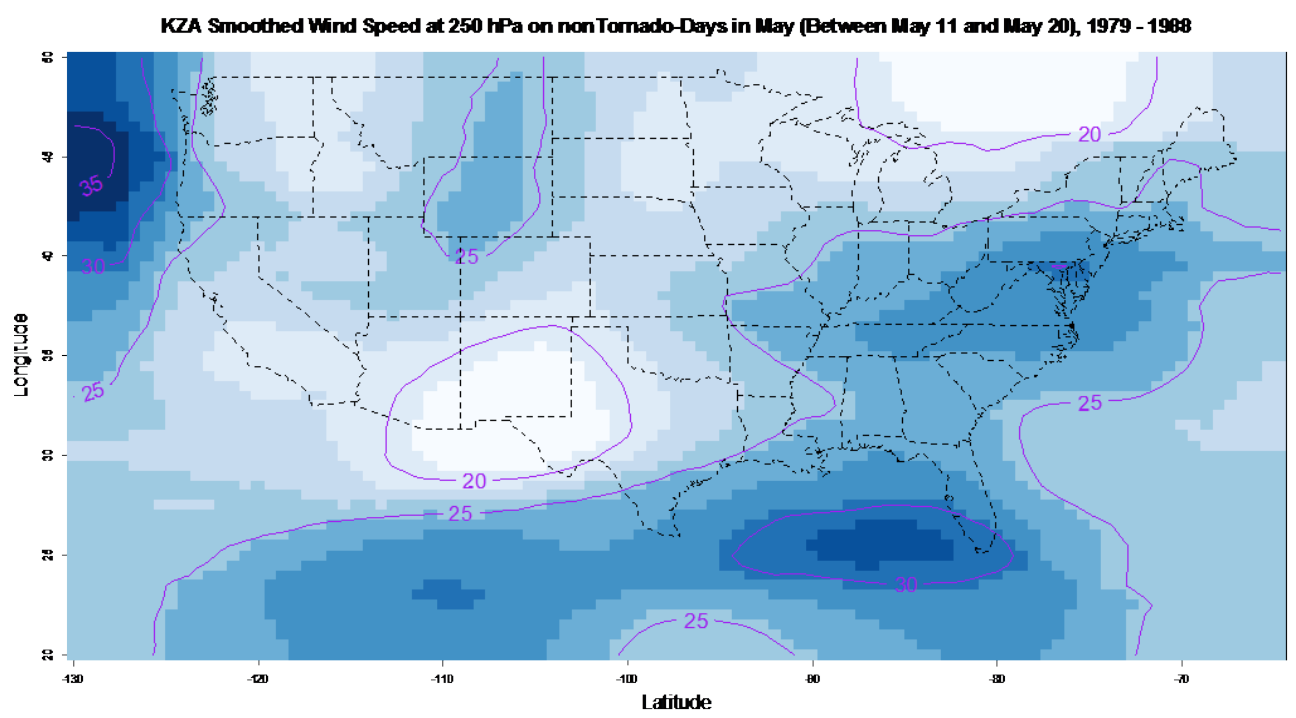

KZA Smoothed Wind Speed at 250 HPa on Tomado-Days in May (After May 20), 1979 - 1998

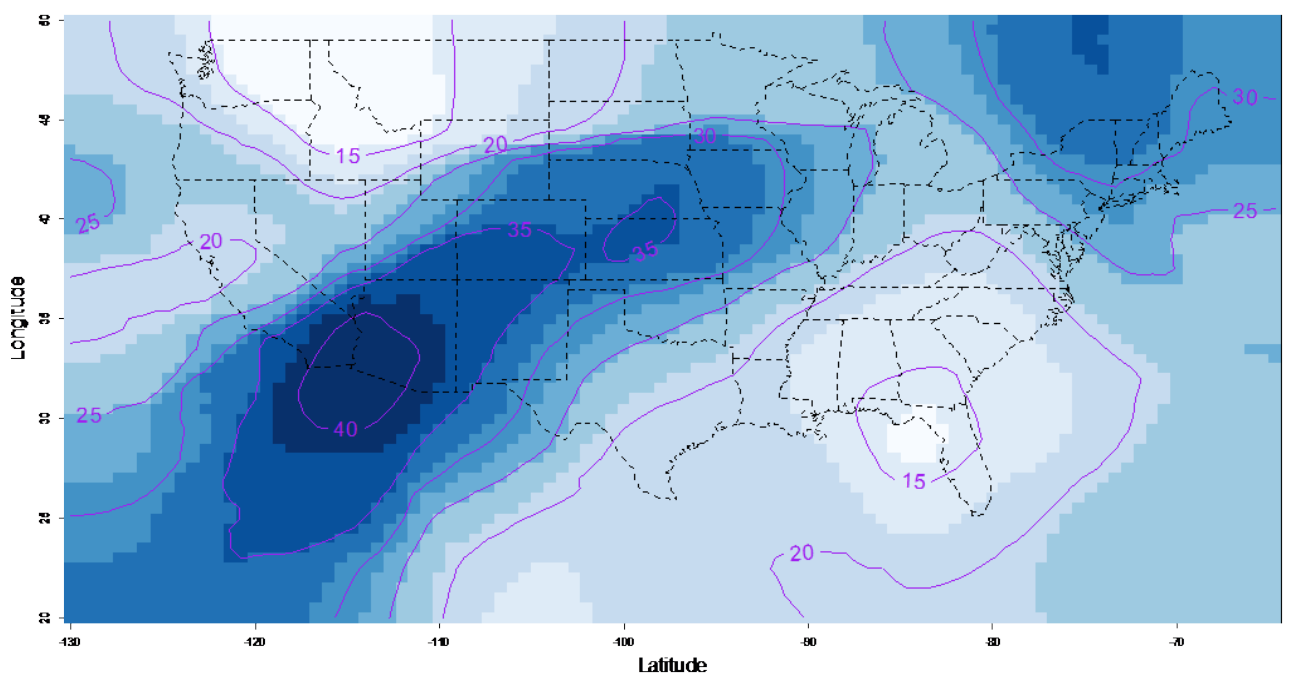

KZA Smoothed Wrid Speed at $250 \mathrm{hPa}$ on nonTomado-Days in May (After May 20), 1979 - 1988

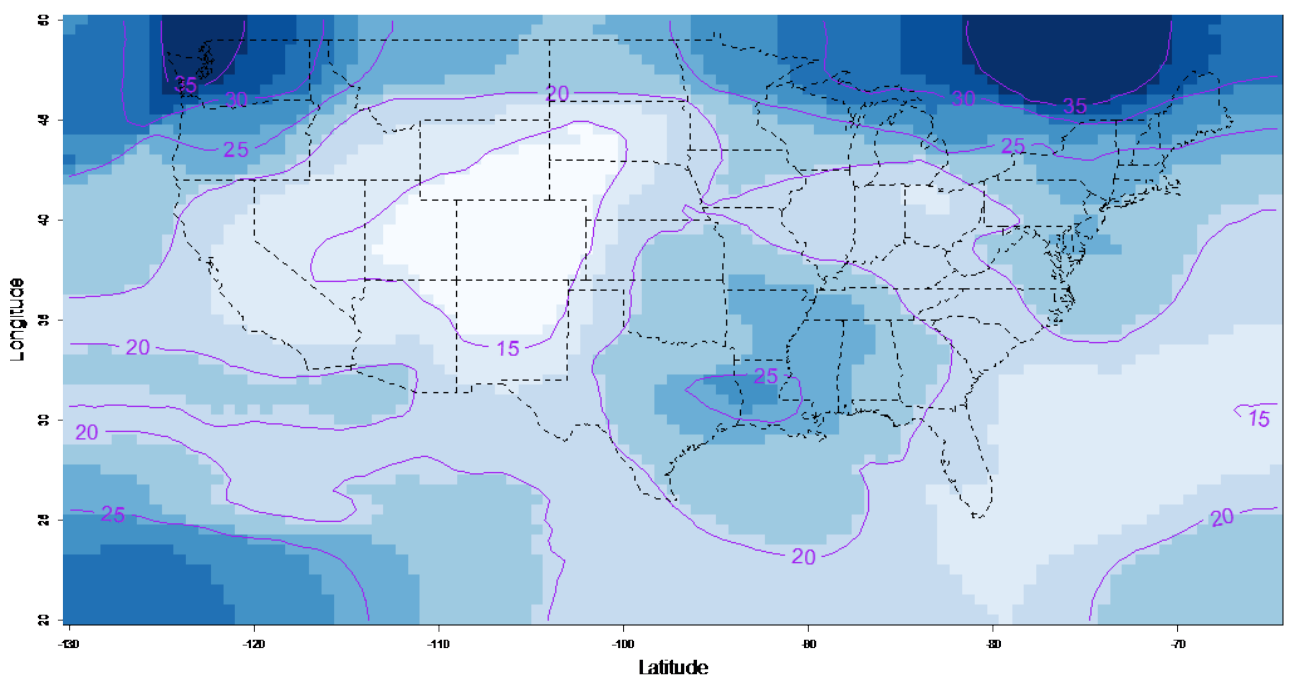

Figure 15. Geographic distribution of jet stream on tornado days and non-tornado days, in the beginning, middle and end of May. 
making strong synoptic disturbances such as thunderstorms and tornados. The synchronousness between jet stream's presence and tornadoes' outbreaks is clearly impressive in terms of their geographic location and timing pace. Acting together more or less synergistically with other factors, jet stream fostered tornado development during the study period from 1979 through 1988; supported by: 1) jet stream was meandering over the tornado alley in the high and relatively high frequency tornado months; 2) hourly tornado frequency concurrently oscillated with diurnal distribution of daily wind maxima; 3) comparisons of spatial distribution of jet stream between tornado days and non-tornado days in May perfectly explained association of jet stream with tornado development. Based on our results, risk factor of tornado accident depends on time of a day, season, area, and counts of top $\mathrm{WS}_{\max }$; it can be calculated to improve accuracy of predictions of dangerous situations.

This study highlights the fact that jet stream is only one of the major trigger factors; so it requires presences of other factors to develop tornadoes. For example, in January and February, even though jet stream was hovering over lower latitudes, but not many tornados were developed, due at least partially, to lack of energy and moisture in the atmosphere, carried by heated water vapor.

Overall, using our 3D KZA filtering technology in this study, we numerically demonstrated the appealing relationship between jet streams and tornado outbreaks in the Central America from 1979 through 1988.

\section{Acknowledgements}

The authors would like to thank Professor Cristina L. Archer at University of Delaware, Dr. Michael G. Bosilovich at National Aeronautics and Space Administration, Professor Fangqun Yu at SUNY Albany for the help with downloading MERRA data.

\section{References}

[1] National Weather Service. http://www.nws.noaa.gov/os/severeweather/

[2] The National Severe Storms Laboratory. http://www.nssl.noaa.gov/

[3] Tornado Project Online. www.tornadoproject.com

[4] Property Casualty 360. U.S. Tornadoes as Deadly, Costly as Hurricanes LIoyd's. http://www.propertycasualty360.com/2013/02/27/us-tornadoes-as-deadly-costly-as-hurricanes-lloyds

[5] Marshall Brain and Robert Lamb. How Tornadoes Work. http://science.howstuffworks.com/nature/climate-weather/storms/tornado1.htm

[6] Roger Edwards. The Online Tornado FAQ. www.spc.noaa.gov/faq/tornado

[7] Zurbenko, I.G. and Sun, M.Z. (2014) High Risk Periods in Tonado Outbreaks in Central USA. Advance in Research, 2, 426-440. http://dx.doi.org/10.9734/AIR/2014/10247

[8] Weather Explained. Vol 1. Tornadoes. http://www.weatherexplained.com/Vol-1/Tornadoes.html

[9] Ziegler, C.L. (2013) A Diabatic Lagrangian Technique for the Analysis of Convective Storms. Part II: Application to a Radar-Observed Storm. Journal of Atmospheric and Oceanic Technology, 30, 2266-2280. http://dx.doi.org/10.1175/JTECH-D-13-00036.1

[10] Kosiba, K., Wurman, J., Richardson, Y., Markowski, P., Robinson, P. and Marquis, J. (2013) Genesis of the Goshen County, Wyoming, Tornado on 5 June 2009 during VORTEX2. Monthly Weather Review, 141, 1157-1181. http://dx.doi.org/10.1175/MWR-D-12-00056.1

[11] Skinner, P.S., Weiss, C.C., Schroeder, J.L., Wicker, L.J. and Biggerstaff, M.I. (2011) Observations of the Surface Boundary Structure within the 23 May 2007 Perryton, Texas, Supercell. Monthly Weather Review, 139, 3730-3749. http://dx.doi.org/10.1175/MWR-D-10-05078.1

[12] Frame, J., Markowski, P., Richardson, Y., Straka, J. and Wurman, J. (2009) Polarimetric and Dual-Doppler Radar Observations of the Lipscomb County, Texas, Supercell Thunderstorm on 23 May 2002. Monthly Weather Review, 137, 544-561. http://dx.doi.org/10.1175/2008MWR2425.1

[13] Corfidi, S., Weiss, S., Kain, J., Corfidi, S., Rabin, R. and Levit, J. (2010) Revisiting the 3-4 April 1974 Super Outbreak of Tornadoes. Weather and Forecasting, 25, 465-510. http://dx.doi.org/10.1175/2009WAF2222297.1

[14] Dunn, L.B. and Vasiloff, S.V. (2001) Tornadogenesis and Operational Considerations of the 11 August 1999 Salt Lake City Tornado as Seen from Two Different Doppler Radars. Weather and Forecasting, 16, 377-398. http://dx.doi.org/10.1175/1520-0434(2001)016<0377:TAOCOT>2.0.CO;2

[15] Zurbenko, I.G. and Luo, M. (2015) Surface Humidity Changes in Different Temporal Scales. American Journal of Climate Change, 4, 226-238. 
[16] National Weather Service. JetStream—Online School for Weather. http://www.srh.noaa.gov/jetstream/tstorms/tornado.htm

[17] Premium Weather. The Jet Stream - Upper Air Flow and Severe Weather. http://www.tornadochaser.net/jet.html

[18] AccuWeather (2011) 150-mph Jet Stream a Key Factor in Wednesday's Tornado Outbreak. http://www.accuweather.com/en/weather-news/150mph-jet-a-key-factor-in-wed/48985

[19] Livescience (2011) Deadly Tornadoes, Floods Blamed on “Superjet” Stream. http://www.livescience.com/30952-alabama-tornadoes-tennessee-floods-superjet-stream.html

[20] Archer, C.L. and Caldiera, K. (2008) Historical Trends in the Jet Streams. Geophysical Research Letters, 35, L08803.

[21] Koch, P., Weirnli, H. and Davies, H.C. (2006) An Event-Based Jet-Stream Climatology and Typology. International Journal of Climatology, 26, 283-301. http://dx.doi.org/10.1002/joc.1255

[22] Yang, W. and Zurbenko, I. (2010) Kolmogorov-Zurbenko Filters. Wiley Interdisciplinary Reviews: Computational Statistics, 2, 340-351. http://dx.doi.org/10.1002/wics.71

[23] WIKIPEDIA. Kolmogorov-Zurbenko Filter. https://en.wikipedia.org/wiki/Kolmogorov\%E2\%80\%93Zurbenko_filter\#

[24] Close, B. and Zurbenko, I. (2015) Kolmogorov-Zurbenko Adaptive Filters, R Software "kza”.

[25] Close, B. and Zurbenko, I. (2008) Time Series Analysis by KZA of the Fatal Analysis Reporting System. In: Proceedings of the Joint Statistical Meeting, Denver, Colorado.

[26] Zurbenko, I., Porter, P., Gui, R., Rao, S., Ku, J. and Eskridge, R. (1996) Detecting Discontinuities in Time Series of Upper Air Data: Development and Demonstration of an Adaptive Filter Technique. Journal of Climatology, 9, 35483560. http://dx.doi.org/10.1175/1520-0442(1996)009<3548:DDITSO>2.0.CO;2

[27] Zurbenko, I.G. and Sun, M.Z. (2015) Associations of Jet Streams with Tornado Outbreaks in the North America. Atmospheric and Climate Sciences, 5, 336-344. http://dx.doi.org/10.4236/acs.2015.53026 